\title{
Microstructural Influences on CVN Toughness in Alloy 706
}

\author{
J.E. Morra \\ Wyman-Gordon Company \\ North Grafton, MA 01536
}

\begin{abstract}
Alloy 706 can be processed according to several different manufacturing routes to yield a variety of microstructures. Use of this alloy for large LBGT forgings necessitates careful forge process definition and microstructural control to achieve optimum properties. One property of interest for this application is charpy v-notch toughness (CVN).
\end{abstract}

Experimental work simulating different forging processes has demonstrated a dependence of CVN on alloy microstructure. Specifically, the influence of eta phase content, as determined by solution heat treatment time, was examined. Carbide distribution and specimen orientation were also studied, and were found to have a significant effect on CVN results 